\title{
Thời COVID, kháng thể nào cho nhũng khát khao được học?
}

\author{
Hoàng Anh Đức* \\ ( *Thành viên Hiệp hội các nhà giáo dục toàn cầu NAFSA)
}

Trong nghiên cứu mới đây về "Ảnh hưởng của COVID-19 tới sự lo âu của sinh viên đại học tại Trung Quốc" trên tạp chí Frontiers in Psychology, hai tác giả Chongying Wang và Hong Zhao (2020) đã phần cuối của bảng khảo sát để người trả lời viết một câu duy nhất về điều mà các em lo ngại nhất. Một trong những từ khoá xuất hiện nhiều nhất là "bắt đầu học kì mới".

Những mùa hè của tuổi học trò như những thảo nguyên đầy màu sắc, những khoảng nghỉ chân của người lữ khách bỗng trở nên ngắn lại. Nỗi buồn là điều khó tránh khỏi khi ta phải xa rời những gì vốn đã quá thân thuộc, ví dụ như một kỳ nghỉ hè. Những mùa hè nào có bao giờ đến và đi một mình mà không để lại những vấn vương đầu đời, những giấc mơ viển vông và cả hoài bão khám phá. Ây thế mà các thứ hành lý kí gửi ấy bỗng chốc trở nên mong manh và bất định bởi COVID19. Những giấc mơ không chỉ tuột khỏi tay mà còn bị thế chỗ bởi các mối lo âu, sợ hãi bất chợt và thậm chí sẽ còn tồn tại dai dẳng. Cảm xúc khi phải xa rời một thứ tưởng chừng đã thân mà lại chưa thuộc về mình thật khó để được gọi tên.

\section{Những giấc mơ bị rút ống thở}

Một học trò cũ của tôi đã quyết định dành cả năm 2019 làm năm gap-year - một năm nghỉ học để khám phá bản thân và thế giới, trước khi bắt đầu học đại học chính thức. So với chục năm về trước, gap-year giờ đã không còn xa lạ gì với học sinh và phụ huynh Việt Nam. Tuy nhiên việc sẵn sàng dành trọn một năm để khám phá và chuẩn bị cho quãng đường học đại học lại không phải việc đơn giản mà bất kì gia đình hay học sinh nào cũng có thể lựa chọn bởi cả lí do tài chính và tâm lý. Trong suốt một năm qua, cô học trò ấy đã nhận dạy thêm gia sư, làm online marketing và nhận các công việc thiết kế tự do để trang trải mọi kinh phí chu du đó đây và học thêm những điều mới. Sự nỗ lực đó là cả một quá trình chứ không đơn thuần là một, hai câu nói. Trước Tết Nguyên đán, em đã rất hào hứng nhờ tôi góp ý về bài luận và hồ sơ xin học bổng. Thời điểm giãn cách xã hội là thời điểm em căng thẳng nhất. Chú ngựa phiêu du phải ngồi cuồng chân ở nhà, đối diện với nỗi lo đa chiều về dịch bệnh và cả lộ trình học tập. Ngày em nhận được thông báo học bổng, cũng là ngày chính phủ Hoa Kỳ ra lệnh tạm ngừng cấp mới visa cho sinh viên quốc tế. Em nói với tôi rằng: "Em có thể dành thêm một năm gap-year nữa để tự mày mò, khám phá, nhưng..."

Những điều đằng sau từ “nhưng” luôn là những điều khó đối diện.

Một bạn trẻ khác, vốn từng rất mừng rỡ và tự hào khi trúng tuyển một chương trình học bổng chính phủ cũng trở nên hụt hẫng vì kế hoạch của mình bị gắn thêm dấu chấm lửng... Mới tháng trước, cậu ấy tung tăng từ bắc tới nam để học những khoá dự bị, để chuẩn bị những năng lực và tâm thế sẵn sàng cho một giai đoạn mới đầy thử thách. Giữa tháng này, chính phủ nước bạn thông báo sẽ hoãn việc nhập học ít nhất đến kỳ mùa xuân năm sau. Công việc tại cơ quan cũ đã tạm ngưng để chuẩn bị cho việc học, anh bạn trẻ bỗng dưng rơi vào trạng thái gap-year một cách thụ động.

Đầu tháng sáu, một người bạn của tôi đang làm nghiên cứu sau Tiến sĩ tại một trường đại học ở châu Âu đã khóc nức nở vì một tình huống vô cùng éo le. Cô đã ở lại Việt Nam sau kì nghỉ Tết nguyên đán, đã rất mừng rỡ vì sự an toàn và ấm cúng của Tổ quốc trong suốt mùa dịch - điều cô thực lòng biết ơn. Thế nhưng, cô không quay trở lại được trường đại học mà mình đang công tác. 
Thêm vào sự diễn biến khó lường của COVID-19 (Khuc et al., 2020), dự án mà cô tham gia đã bị cắt giảm kinh phí. Là một nhà nghiên cứu chưa vào biên chế, lại đang không hiện diện ở nước sở tại, hợp đồng của cô bị đưa vào diện không được gia hạn. Những dự định của cô bỗng chuyển từ hứa hẹn sang tuyệt vọng. Giá mà cô không phải bận tâm về gia đình, để có thể tạm dừng lại một thời gian nhằm làm mới tinh thần, năng lực và đa dạng hoá kinh nghiệm của bản thân. Vị trí nghiên cứu viên trong một dự án khoa học không phải dễ dàng tìm được, nhất là trong bối cảnh dịch bệnh còn diễn biên phức tạp (Vuong and Ho, 2020). Không giống như những bạn sinh viên mười tám, đôi mươi, gap-year là thứ quá xa xỉ có thể xuất hiện trong tâm tưởng của cô.

Đó chỉ là ba ví dụ lẻ loi trong số vô vàn những nghịch cảnh mà học sinh, sinh viên, học viên sau đại học trên khắp thế giới đang phải đối mặt. Theo khảo sát mà các đồng sự của tôi tại EdLab Asia tiến hành vào đầu tháng 5 với 410 du học sinh, có tới $43.15 \%$ kế hoạch du học của học sinh, sinh viên Việt Nam bị huỷ bỏ hoặc phải hoãn lại chưa rõ thời hạn. Dưới 15\% du học sinh được khảo sát nhận được các thông tin về các phương án học tập trực tuyến đối với học kì mùa thu 2020. Trong sự rối ren ấy, chỉ $5.12 \%$ du học sinh được khảo sát nhận được các hỗ trợ về tâm lý từ nhà trường. Tuy nhiên, phần lớn trong số đó là các sinh viên đang theo học, còn những tân sinh viên của năm học 2020-2021 thì hầu như không nhận được sự hỗ trợ nào về tâm lý.

\section{Những cuộc đua không bền vững}

Mỗi gia đình, mỗi học sinh có một sự lựa chọn riêng cho con đường học tập. Sự lựa chọn ấy là tổng hoà các yếu tố văn hoá, kinh tế, xã hội của mỗi gia đình. Nếu ai nấy đều vui vẻ với lựa chọn của riêng mình, sẽ không có vấn đề gì cả. Thế nhưng trong những giai đoạn khủng hoảng, thật khó lòng để học sinh hay phụ huynh có thể đưa ra được những chọn lựa trong yên bình.

Mùa hè thường là khoảng thời gian chúng ta lo ngại nhiều về việc xảy ra tình trạng đuối nước hoặc các tai nạn thương tích. Bên cạnh đó, là những lo âu về chuyện học thêm, ôn luyện vào trường nọ lớp kia, chạy đua thành tựu và cạnh tranh các học bổng. Bởi mối nguy COVID-19, chúng ta quan tâm hơn đến sức khoẻ thể chất của con cái mình, nhưng cũng đồng thời đẩy các em vào những guồng đua mới. Cùng với giãn cách xã hội, nhiều kỳ thi chuẩn hoá như IELTS, TOEFL, SAT, và GRE... đã bị hoãn lại nhiều tháng, trên quy mô toàn cầu. Khi mối lo ngại về con đường học vấn trong và sau mùa dịch nổi lên, chúng ta lại chứng kiến sự ngập tràn quảng cáo về các chương trình dự bị, du học tại chỗ, chẳng hề thua kém các quảng cáo bán bảo hiểm - đều đánh vào nỗi sợ những bất định trong tương lai và khả năng chấp nhận rủi ro thấp.

Bên cạnh những hiểm nguy rình rập, COVID-19 cũng đã cho chúng ta thấy vẻ đẹp trong những nét tái tạo của thiên nhiên. Do vắng bóng con người, bầu không khí ở nhiều vùng công nghiệp đã trong xanh trở lại, cá heo và thiên nga xuất hiện trên những kênh đào ở Venice sau 60 năm, nhiều loại rùa quý hiếm đã xuất hiện và đẻ trứng trên các bãi biển Thái Lan. Chúng ta không khỏi giật mình khi đón nhận thông điệp của thiên nhiên để nhìn nhận lại cuộc đua khai thác thiên nhiên chưa nhìn thấy điểm dừng nhưng đã rõ mười mươi kết cục. Bên cạnh cuộc đua khai thác các tài nguyên hữu hình đó, cuộc đua về những tài nguyên vô hình cũng khốc liệt chẳng kém. Một trong những thứ tài nguyên vô hình được ưa chuộng nhất, chính là các cơ hội giáo dục.

Những vấn đề bất bình đẳng về giáo dục ở các quốc gia khác nhau thường được lý giải bởi hai học thuyết xã hội học chủ đạo: MMI (Maximally Maintained Inequality - Sự bất bình đẳng được duy trì tối đa) và EMI (Effectively Maintained Inequality - Sự bất bình đẳng được duy trì hiệu quả) 
(Raftery và Hout, 1993). Thuyết MMI cho rằng sự ảnh hưởng của nền tảng gia đình chỉ suy giảm khi mà nhu cầu của giới giàu đối với một loại hình/mức độ giáo dục nhất định trở nên bão hoà, phổ quát. Khi ấy, hình thức giáo dục đó mới lan toả và mang lại lợi ích cho những tầng lớp kinh tế thấp hơn. Vì thế, một nhu cầu, sản phẩm giáo dục "cao cấp" rồi cũng sẽ được bình dân hoá, nhưng sẽ mất nhiều thời gian. Đơn cử như việc học thêm tiếng Anh với giáo viên bản xứ, vốn là lựa chọn xa xỉ vào cuối thập nhiên 90 , giờ đã trở nên phổ biến ở hầu hết các đô thị.

Lucas (2001) cho rằng thuyết MMI đã không lý giải được thực trạng của Mỹ và Hà Lan, nơi mà tác động của gia cảnh đến thành quả giáo dục đã giảm mạnh, ngay cả trước khi đạt được điều kiện về sự bão hoà của một nhu cầu nhất định. Ông đề xuất học thuyết EMI, xem xét các thành quả, các cơ hội tiếp cận giáo dục về cả số lượng và chất lượng. Lucas cho rằng, ngay cả khi các nhu cầu đã trở nên phổ quát, tầng lớp thượng lưu vẫn tìm kiếm những khía cạnh khác biệt về chất lượng để tách biệt mình khỏi phần đông xã hội và duy trì đẳng cấp.

Trong thời đại toàn cầu hoá, sự cách biệt trong giáo dục toàn cầu không chỉ hiện hữu trong những hoạt động học tập, mà cả trong các hoạt động ngoại khoá. Rất khó nhận ra sự khác biệt về mục tiêu, hoạt động và tâm thế mà phụ huynh lẫn học sinh dành cho các học kì chính khoá và các kì nghỉ. Ranh giới giữa kì học và kì nghỉ, có lẽ chỉ đơn thuần được đánh dấu bằng các bài kiểm tra cuối năm. Trong bối cảnh ứng phó với COVID-19, ranh giới đó bỗng trở thành vạch xuất phát của nhiều cuộc đua nước rút mà trong đó học sinh phải chạy đua với người khác; với kì vọng của bố mẹ, thầy cô, bạn bè, họ hàng, làng xóm, mạng xã hội; chạy đua với chính mình, và với từng chiếc kim đồng hồ đang tích tắc như nó đã, đang, và vẫn sẽ cứ tích tắc. Điểm chung giữa loài virus đang gieo rắc mối lo ngại về sức khoẻ nhân loại, và những áp lực đang đè nén lên học sinh mọi độ tuổi, có lẽ là ở xuất xứ: chúng đều là sản phẩm của chính chúng ta, là hệ quả của những khát khao không bền vững. 


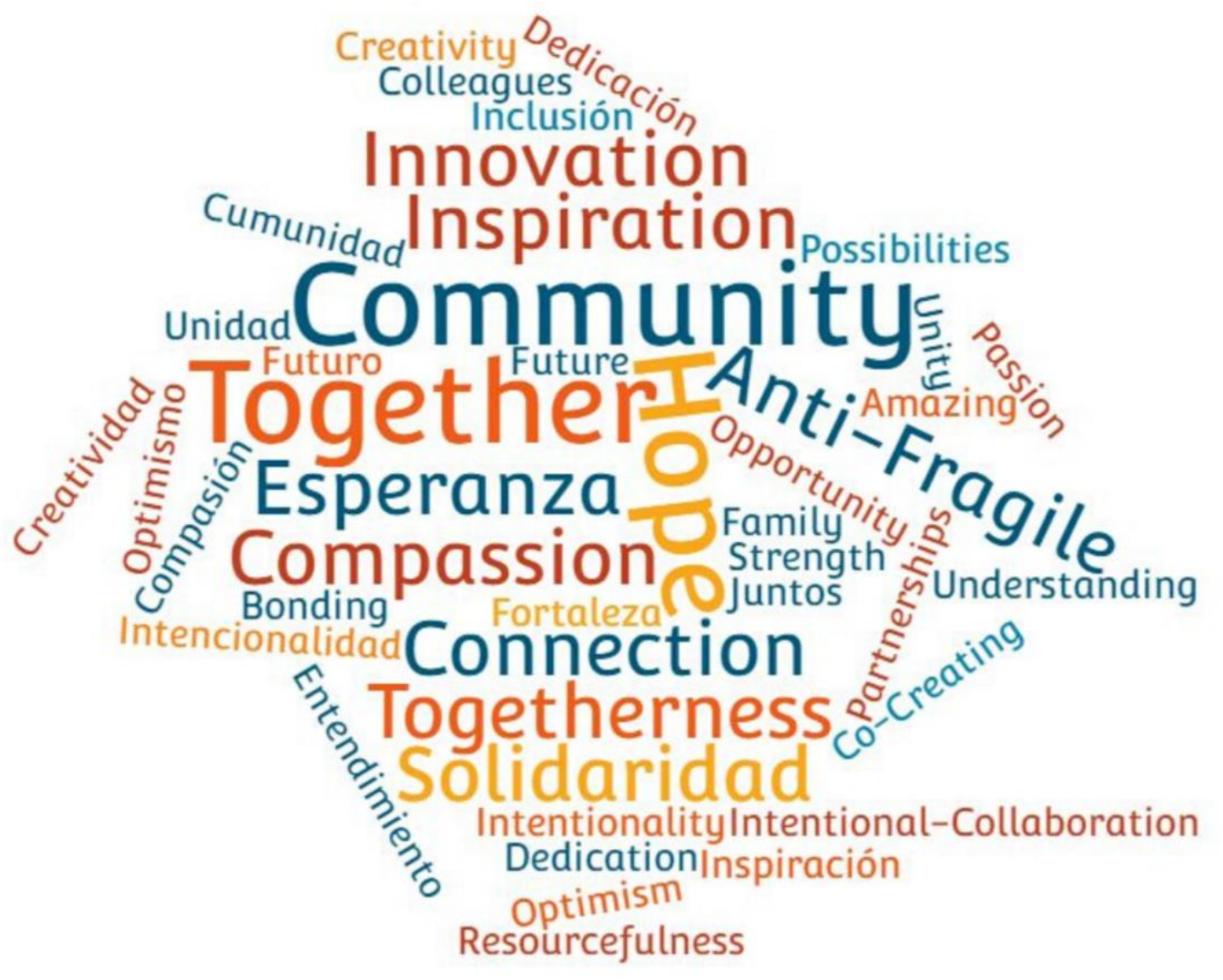

Hình 1. Nhũ̃ng điều cần thiết để đối phó với tình trạng khủng hoảng giáo dục tiện tại-Các tì khoá xuất hiện nhiều nhất trong toa đàm của Hiệp hội các nhà giáo dục toàn cầu NAFSA, ngày $17 / 6 / 2020$.

\section{Kháng thể nào cho những khát khao?}

Không chỉ học sinh, sinh viên mà cả giáo viên cũng đang đương đầu với nhiều áp lực tâm lý do tác động của COVID-19. Khảo sát của chúng tôi với 373 giáo viên các cấp tại Hà Nội (Vu et al., 2020) vào tuần đầu tháng 4 ghi nhận $37,8 \%$ giáo viên cảm thấy mệt mỏi vì các xáo trộn do COVID19 , và $53,6 \%$ giáo viên có lo lắng về sự khó khăn kinh tế trong thời gian sắp tới. Trong một khảo sát khác với 307 giáo viên nước ngoài đang giảng dạy tại các nước Đông Nam Á (Hoang et al., 2020), chúng tôi ghi nhận $45,6 \%$ cho rằng họ bị kì thị bởi người bản xứ vì những lo ngại liên quan đến COVID-19 (Hoang, 2020). Khi chính bản thân giáo viên cũng đang bị bủa vây bởi các căng thẳng, liệu các hoạt động và kết quả giáo dục sẽ tươi đẹp và không bị nhuốm màu căng thẳng?

Kể từ giữa tháng 3 - khi đại dịch COVID-19 bắt đầu lan rộng ra nhiều nước trên thế giới, các cuộc thảo luận về chuyên môn trên diễn đàn Hiệp hội các nhà giáo dục toàn cầu NAFSA đã bắt đầu xoay quanh những ảnh hưởng đối với các hệ thống giáo dục. Những mối lo ngại ban đầu về quá trình chuyển đổi số như một giải pháp tạm thời đã dần nhường chỗ cho mối lo ngại về tình hình tuyển sinh và tính bền vững của các chương trình học cho sinh viên quốc tế. Đối với các trường đại học có mức độ quốc tế hoá cao, sinh viên quốc tế đóng vai trò thiết yếu về cả phương diện tài chính, lẫn sự đa dạng văn hoá của từng trường. 
Trong phiên thảo luận bàn tròn ngày 17/6 với chủ đề "Thiết kế trải nghiệm học tập liên văn hoá: Quan hệ đối tác sáng tạo; Quan hệ ảo toàn cầu và địa phưong”, các diễn giả đã đi đến đồng thuận với nhiều quan điểm để đảm bảo chất lượng giáo dục dưới tác động của COVID-19. Ý tưởng đạt được nhiều sự tán thành nhất chính là: "Hoc sinh không cần phải đi du học để có được những lợi ích tù các trải nghiệm quốc tế. Các giảng viên có thể thiết kế một chuơng trình giảng dạy phù hợp với cộng đồng địa phương và giúp người học tiếp cận với những trải nghiệm mới."

Bên cạnh đó, các trao đổi cũng đề cập tới ba thông điệp đáng chú ý dành cho các trường đại học địa phương trong quá trình tự xây dựng các kịch bản ứng phó của mình, hỗ trợ các du học sinh bị ảnh hưởng do COVID-19. Thông điệp thứ nhất: "Hãy lấy sư chiêm nghiệm của người học làm trọng tâm để kết nối các trải nghiệm học tập. " Cụ thể, việc đầu tiên mà các trường đại học cần làm là tiến hành đánh giá về các nhu cầu thực sự của người học. Kế đến, cần thiết lập những không gian an toàn trong thực tại cũng như trực tuyến, phát triển các mối quan hệ đối tác nhằm mở rộng các cơ hội cho sinh viên. Thay vì việc đưa các em ra ngoài thế giới, hãy tìm cách đưa thế giới đến với các em. Ngoài ra, bên cạnh việc tăng cường các hoạt động tham vấn học đường dành cho sinh viên, các trường đại học cũng nên xem xét việc tăng cường các hoạt động về tâm lý cho phụ huynh, từ đó giảm bớt các áp lực đè nén lên sinh viên.

Thông điệp thứ nhì: "Bản thân nhà trương phải có sụ thich ưng, nhanh nhạy trong việc thiết kế các trải nghiệm học tập để có thể châm ngòi cho nhũng sáng tạo bất ngờ trong nghịch cảnh." Thay vì bắt sinh viên phải tuân thủ theo lộ trình học tập thông thường, các trường đại học nên tăng cường các hoạt động mới, mang tính sáng tạo, xoay quanh những vấn đề mới phát sinh trong mùa dịch. Các bài tập lý thuyết có thể được xem xét và thay đổi bằng những dự án thực hành, tác động trực tiếp tới cộng đồng mà các em đang sinh sống. Bằng việc hướng đến gia đình, bạn bè và cộng đồng với tâm thế họ là những người cần được giúp đỡ, sinh viên không chỉ giải toả được áp lực tâm lý tự thân, mà còn nhận được sự chia sẻ, thấu hiểu từ mọi người.

Cuối cùng, "Hãy tổ chức các nhóm học tập với sụ đa dạng về đặc điểm cá nhân và khuyến khích học trò cùng làm việc hướng tới mục tiêu chung: nhũng trải nghiệm học tập mới, thay vì chỉ nhìn vào điểm số. " Đánh giá quá trình chuyển đổi số trong giai đoạn đầu bùng phát COVID-19, các chuyên gia cho rằng đó là giai đoạn "emergency learning - học tập trong tình huống khẩn cấp", chứ chưa hẳn là "online learning - học tập trực tuyến”. Để triển khai được học tập trực tuyến hiệu quả, các biện pháp kỹ thuật phải được bắt nguồn từ gốc rễ sư phạm. Sự áp dụng công nghệ một cách máy móc có thể đem lại những hiệu quả ngược và tâm lý chán nản, nhất là khi nó được áp dụng kèm theo kì vọng về điểm số. Thay vì được tin tưởng như những trợ thụ đắc lực, công nghệ có thể bị thù ghét bởi những áp lực mà thầy và trò không mong đợi. Nhà trường và gia đình không nhất thiết phải áp dụng triệt để công nghệ cho mọi hình thức học tập, mà có thể cân nhắc những khoảng thời gian để người học tự học tập, trải nghiệm và cộng tác mà không cần dùng tới công nghệ.

Giáo dục không phải là hệ thống nội dung, chương trình hay các bài kiểm tra. Mỗi thế hệ đều có những giá trị nhất định mà chúng ta tin rằng mình nên bảo tồn và truyền lại cho thế hệ sau (Hoang et al., 2020). Giáo dục không chỉ giúp cho quá trình lựa chọn và chuyển tiếp ấy được diễn ra, mà còn giúp cho những thế hệ sau có khả năng tạo ra và phát triển những hệ giá trị của riêng mình. Bốn thông điệp kể trên chỉ là những gợi ý nhất thời để khoả lấp chỗ trống về trải nghiệm thực tế 
mà các du học sinh có thể bị mất đi do ảnh hưởng của COVID-19. Theo một góc độ nào đó, đó sẽ là những cải tổ mang tính chiến thuật để giúp cho các trường đại học địa phương và quốc tế có thể giữ được mối liên hệ chặt chẽ với sinh viên hiện tại và các sinh viên tiềm năng. Ở một góc độ rộng hơn, chúng ta cần sự cảm thông và chia sẻ với giới trẻ về các khó khăn mới xuất hiện, thay vì những câu cảm thán hay hỏi dò xã giao nhiều ẩn ý như "Bao giờ thì cháu đi nước ngoài? Vì COVID nên không đi du hoc à??"

“Một học kì mới” không nên là nỗi sợ của một ai, bất kể độ tuổi, sắc tộc, tín ngưỡng. Cho dù được bắt đầu dưới dạng thức nào, "một học kì mới" cũng cần những niềm vui, sự hứng khởi và khát khao (Hoang et al., 2020). Chúng ta đều biết rằng vaccine cho những bệnh truyền nhiễm được tạo ra dựa trên cơ chế ghi nhớ và tạo ra các kháng thể. Để làm ra những liều vaccine cho tinh thần, cho khát khao và đam mê chính đáng - đam mê được học, có lẽ kháng thể hữu hiệu nhất chính là tinh thần thấu hiểu, sẻ chia và tương trợ.

Tài liệu được trích dẫn:

Hoang, A.D., 2020. Pandemic and teacher retention: empirical evidence from expat teachers in Southeast Asia during COVID-19. International Journal of Sociology and Social Policy.

Hoang, A.D., Pham, H.H., Nguyen, Y.C., Vuong, Q.H., Dam, M.Q., Tran, T. and Nguyen, T.T., 2020. Introducing a tool to gauge curriculum quality under Sustainable Development Goal 4: The case of primary schools in Vietnam. International Review of Education, 66(4), pp.457-485.

Hoang, A.D., Nguyen, Q.N., Chi, N.L., Dao, Q.A., Doan, P.T.T., Dinh, T.T., Ta, H.T., Quach, L.A. and Tran, D.H., 2020. Sổ tay Nâng cao sức khoẻ tinh thần trong mùa dịch.

Hoang, A.D., Ta, N.T., Nguyen, Y.C., Hoang, C.K., Nguyen, T.T., Pham, H.H., Nguyen, L.C., Doan, P.T., Dao, Q.A. and Dinh, V.H., 2020. Dataset of ex-pat teachers in Southeast Asia's intention to leave due to the COVID-19 pandemic. Data in brief, 31, p.105913.

Khuc, Q.V., Phu, T.V. and Vuong, Q.H., 2020. The pathways and conditions of effectively combating the COVID-19 pandemic in Asia (No. dmkre). Center for Open Science.

Lucas, S.R., 2001. Effectively maintained inequality: Education transitions, track mobility, and social background effects. American journal of sociology, 106(6), pp.1642-1690.

Raftery, A.E. and Hout, M., 1993. Maximally maintained inequality: Expansion, reform, and opportunity in Irish education, 1921-75. Sociology of education, pp.41-62.

Vu, C.T., Hoang, A.D., Than, V.Q., Nguyen, M.T., Dinh, V.H., Le, Q.A.T., Le, T.T.T., Pham, H.H. and Nguyen, Y.C., 2020. Dataset of Vietnamese teachers' perspectives and perceived support during the COVID-19 pandemic. Data in Brief, p. 105788.

Vuong, Q.H., 2020. Reform retractions to make them more transparent.

Vuong, Q.H. and Ho, M.T., 2020. Rethinking editorial management and productivity in the COVID-19 pandemic. European Science Editing, 46, p.e56541.

Wang, C. and Zhao, H., 2020. The Impact of COVID-19 on Anxiety in Chinese University Students. Frontiers in Psychology, 11, p.1168. 